\title{
Portal Venous System
}

National Cancer Institute

\section{Source}

National Cancer Institute. Portal Venous System. NCI Thesaurus. Code C33344.

A system of vessels in which blood, after passing through one capillary bed, is conveyed through a second set of capillaries before it returns to the systemic circulation. It pertains especially to the hepatic portal system. 